\title{
EXTRAÇÃO DO ÓLEO E RESINAS DE GENGIBRE ENCONTRADO NO LITORAL PARANAENSE (Zingiber officinale Roscoe)
}

\author{
ARION ZANDONÁ FILHO * \\ ANTONIO L. MURTA **
}

\begin{abstract}
Este trabalho descreve os processos utilizados para a obtenção do óleo e da resina de gengibre, extraídos do seu rizoma "in natura" e processado. Os ensaios foram efetuados com rizoma "in natura", colhido, lavado e mantido sob refrigeração até o momento do uso e seco em estufa de ar forçado até redução da umidade a $10 \%(\mathrm{~m} / \mathrm{m})$ e finalmente estocado sob refrigeração. Os processos de obtenção do óleo e resinas envolveram a extração com solventes orgânicos, além de extração de óleos voláteis por arraste de vapor. Os resultados mostraram que a melhor qualidade do óleo é obtida pelo processo de arraste de vapor, com tempo de extração de 2 horas, e que a maior quantidade de resina é obtida utilizando a propanona como solvente e tempo de extração de 3 horas.
\end{abstract}

\section{INTRODUÇÃO}

\subsection{HISTÓRICO}

As plantas aromáticas e seus sub-produtos têm atraído a atenção de pesquisadores do mundo inteiro, por suas propriedades medicinais e organolépticas $(1,3,34)$. O gengibre, por apresentar estas propriedades, já era conhecido e mencionado por Confúncio (551-479 A.C.), pelo médico grego Dioscorides e pelo Alcorão. Na Europa, já era conhecido há mais de 2.000 anos $(25,32)$. É uma planta herbácea, da família das "Zingiberáceas", nativa da Índia (Ásia), podendo atingir até 1,20 m de altura. Não apresenta raízes, e sim, numerosos rizomas, dos quais são extraídos elementos resinosos, bastante aromáticos e de gosto picante, motivo pelo qual é empregado na preparação de condimentos, temperos, etc $(14,23,25)$.

* Professor, Faculdade de Ciências Exatas e Tecnológicas, Universidade Tuiuti do Paraná, Curitiba, PR, Brasil.

** Professor Aposentado da Universidade Federal do Paraná. 
A planta presta-se para a fabricação de produtos alimentícios e de perfumaria, como o caso do "ginger ale", refrigerante muito consumido nos Estados Unidos da América. O gengibre é bastante conhecido no Brasil como ingrediente do famoso quentão, muito apreciado durante as festas juninas, de alguns produtos farmacêuticos e de confeitaria (7). Especialmente na Bahia é utilizado em pratos tradicionais, como o "vatapá", "carurú" e "efs" $(3,31)$.

Conhecem-se várias espécies de gengibre, como por exemplo, o "gengibre dourado" (Zingiber Chrisantum) e o "gengibre-da-terra" (Hedychyum garderianum). No Brasil, acredita-se que o gengibre tenha sido introduzido pelos holandeses, pois na época do domínio holandês era grande a permuta e a introdução de plantas econômicas entre os dois países, sabendo-se que, no ano de 1.587, a produção brasileira alcançou o volume de 4.000 toneladas $(15,25,33,34)$.

Devido ao seu largo espectro de utilização, a demanda do gengibre vem aumentando ao longo dos tempos, sendo que a utilização do seu óleo tem se destacado consideravelmente neste contexto $(15,20,21)$.

No Quadro 1 são apresentados os valores, expressos em reais ( $r \$$ ), obtidos nas safras de 1994 a 1998 e declarados ao Banco Central do Brasil (37).

\section{QUADRO 1 - RESULTADO POR SAFRA EM REAIS DA PRODUÇÃO NACIONAL DE GENGIBRE (PROAGRO)}

\begin{tabular}{|cccc|}
\hline Safra 94/95 & Safra 95/96 & Safra 96/97 & Safra 97/98 \\
\hline 906.133 & 4.933 & 3.951 & 2.494 \\
\hline
\end{tabular}

Fonte: Banco Central do Brasil - DEORF / DIRAI (37).

Valores desprezados os centavos.

Considera-se como resultado a diferença entre o valor do adicional e o somatório de coberturas e custas periciais.

Pode-se observar que as safras dos últimos cinco anos mostram variação significativa e tendência decrescente. No Estado do Paraná o município de Morretes é o principal produtor do rizoma de gengibre (Quadro 2).

Apesar da produção apresentar decréscimo, o Brasil produz mais gengibre do que consome, exportando o excedente, em quantidades variadas e permanecendo entre os dez maiores exportadores do mundo. 


\section{QUADRO 2 - PRODUÇÃO AGRÍCOLA NO MUNICÍPIO DE MORRETES 1995/96 (37)}

\begin{tabular}{|l|r|}
\hline DISCRIMINAÇÃO & QUANTIDADE \\
\hline Área Total do Município de Morretes & $66.270 \mathrm{ha}$ \\
\hline Número Total de Produtores & 1.161 \\
\hline Área de Lavouras & $1.875 \mathrm{ha}$ \\
\hline $\mathrm{N}^{\circ}$ Pequenos Produtores (até 50 ha) & 45 \\
\hline Área de Reflorestamento & $750 \mathrm{ha}$ \\
\hline $\mathrm{N}^{\circ}$ Médio Produtores (de 50.1 a 250 ha) & 93 \\
\hline Área de Pastagens & $2.920 \mathrm{ha}$ \\
\hline $\mathrm{N}^{\circ}$ Grandes Produtores (acima de 250 ha) & 23 \\
\hline Área de Matas & $54.655 \mathrm{ha}$ \\
\hline Outras áreas & $6.070 \mathrm{ha}$ \\
\hline Lavouras de gengibre (número de Produtores) & 85 \\
\hline Área Plantada de gengibre (ha) & 140 \\
\hline Rendimento Médio de gengibre (Kg/ha) & 20.000 \\
\hline Produção Total de gengibre (t) & 2.800 \\
\hline \% de área plantada no Município & 7,5 \\
\hline
\end{tabular}

No setor de exportação do óleo de gengibre, o Brasil não conta com unidades industriais, nem tampouco que avaliem consideravelmente os diferentes processos de extração, seleção de matéria-prima ou a caracterização do óleo produzido $(33,35)$.

\section{2 ÓLEO}

O óleo volátil de gengibre é produzido por destilação ou por arraste de vapor, do gengibre seco. Ao contrário de outros óleos essenciais, utilizados na produção de perfumes, os quais são produzidos e imediatamente após a colheita vão integrar a industrialização, o óleo de gengibre é largamente produzido por importadores do rizoma seco que, em alguns casos, nem sequer plantam o vegetal. Os aromas do gengibre seco e fresco (cru) são significativamente diferentes $(3,16,35)$. A China e a Índia têm exportado quantidades consideráveis de óleo, por serem identificados separadamente no comércio, enfatizando sua superioridade diante dos demais, por serem produzidos no local da colheita $(30,36)$.

A maior parte dos rizomas exportados pelos maiores produtores (China, Índia, Ceilão e outros) é consumida pelas indústrias, especialmente nos Estados Unidos da América, Inglaterra e Alemanha. Dependendo do processo de extração, o rendimento do óleo em relação ao rizoma seco varia, normalmente, de 1 a 2,5\% $(\mathrm{m} / \mathrm{m})$. Seu aroma também varia em qualidade e intensidade. No Reino Unido por exemplo, quando utilizado 
seletivamente, em bebidas, há preferência pelo óleo com distinto toque de limão $(6,14,16,21,24)$. Este aroma parece ser, satisfatoriamente obtido, com o gengibre seco. Os preços variam conforme o emprego de cada produto $(16,19,31)$.

As características físico-químicas, no entanto, não conservam a qualidade do aroma, podendo a mesma variedade apresentar diferentes aromas, desde que o processo de secagem não seja semelhante $(11,12,14,28$, 33).

Os trabalhos na área mostram melhor rendimento quando se usa o material "in natura", sendo a melhor qualidade de óleo obtida com o gengibre fresco cru e com o liofilizado (13). No entanto, estes dois procedimentos não são economicamente viáveis, já que o gengibre fresco leva muitas horas na destilação e a liofilização requer equipamentos muito onerosos.

A secagem do rizoma ao sol provoca perda do aroma suave de limão, ao longo do tempo. Os melhores resultados obtidos na secagem ocorreram em estufas, com fluxo de ar em contra corrente, na temperatura de $60{ }^{\circ} \mathrm{C}$ em carga na bandeja de $10 \mathrm{~kg} / \mathrm{m}^{2}(11)$.

A literatura sugere que redução em $90 \%$ da umidade é obtida em 12 horas, resultando em óleo de excelente qualidade, com leve aroma de limão, muito superior à obtida com a secagem ao sol $(6,11,12,14,16,29)$. Outro importante aspecto a ser considerado na escolha da matéria-prima é a concentração de óleo. Bons rendimentos têm sido creditados à variedade "Rio de Janeiro", que apresenta concentração média de 1,7\% em relação ao rizoma (14). Algumas variedades e seus aromas característicos são apresentados no Quadro 3.

\section{QUADRO 3 - PRODUÇÃO DE ÓLEO E CARACTERÍSTICAS DO ODOR} (21)

\begin{tabular}{|l|l|l|}
\hline VARIEDADE & $\begin{array}{l}\text { PRODUÇÃO } \\
\text { ÓLEO }\end{array}$ & ODORES CARACTERÍSTICOS \\
\hline Austrália & 2,5 & Aroma suave, cítrico, quente, verde \\
\hline China & 2,5 & Suave, aromático, limolínico \\
\hline Cochinchina & $1,5-2,5$ & Doce, quente, notação distinta de limão \\
\hline Jamaica & 1,0 & Doce, quente, delicado \\
\hline
\end{tabular}

No processo de destilação, após a seleção do rizoma, efetiva-se a remoção do material contaminante e se processa a moagem. Obtém-se bom resultado na trituração do gengibre, seco e duro, se a moagem for efetuada em fatias, num moinho de disco. Na remoção das impurezas, os 
cuidados deverão ser redobrados para não danificar o vegetal e evitar o contato com o solo, propiciando a redução do óleo pela oxidação dos voláteis. Para a destilação a vapor, o equipamento utilizado deve evitar o desenvolvimento de odor caracterizado como "queimado", em vista da elevada quantidade de amido contida nos rizomas. São poucas as informações que relacionam o tempo de destilação com a qualidade do óleo obtido, cujas variações no tempo vão desde alguns minutos até $20 / 30$ horas. Sabe-se que ocorrem mudanças nos terpenóides, especialmente nos álcoois e ésteres, durante a destilação, o que pode se constituir num problema se a pretensão é se obter um óleo com verdadeiro aroma de gengibre. Isto significa que a destilação da resina apresenta vantagem, em comparação com a do rizoma, pela menor duração de tempo na destilação do produto. No óleo obtido neste processo, existe grande concentração de sesquiterpenos, de alto ponto de ebulição, os quais são suscetíveis à oxidação e permutações poliméricas $(5,6,18)$.

Apesar das experiências efetuadas, até agora não existem substitutos sintéticos adequados que consigam reproduzir, integralmente, o aroma natural da planta $(1,3)$.

O extrato alcóolico dos rizomas serve, em grande escala, para aromatizar gasosas e outras bebidas. No campo farmacêutico é conhecido como excitante estomacal e carminativo. Muito antes de ser conhecido nas Américas, os árabes o utilizavam como afrodisíaco e expectorante $(14,17)$. Sob sua epiderme ou casca, encontra-se um tecido constituído por numerosas glândulas de óleo resinosas, o qual encerra a maior parte do princípio ativo que a planta contém. Este óleo essencial é extraído a vapor e fornece $2 \%$ a $3 \%$ de essência, cujos componentes principais são o fenantreno e o canfeno com larga aplicação na indústria de perfumes.

O presente trabalho descreve os processos utilizados para a obtenção do óleo e da resina de gengibre, extraídos do seu rizoma "in natura" e processado.

\section{MATERIAL E MÉTODOS}

\subsection{MATÉRIA-PRIMA}

Os rizomas empregados na extração do óleo de gengibre foram obtidos no município de Morretes, região de Antonina, no litoral paranaense. O gengibre foi plantado em abril e colhido em dezembro, sendo, a seguir, utilizado na realização dos ensaios. O vegetal apresentava aparência agradável, cor amarelada, poucas raízes de cor branca, boa textura com consistência, não apresentando porções deterioradas ou qualquer outro tipo de doença. 


\subsection{PREPARO DO RIZOMA PARA ESTOCAGEM}

O processamento para obtenção do óleo de gengibre requer cuidados especiais no preparo para a conservação do rizoma, a fim de preservar sua textura e não alterar sua composição química.

A matéria-prima (rizoma) utilizada continha pequena quantidade de terra aderida a sua pele, a qual foi retirada com escova e lavagem em água corrente, até que se obtivesse material limpo, sem contaminantes visíveis, para o processo de extração de óleo. Este material foi estocado em congelador e retirado somente no instante da utilização, para não se perder os voláteis por metabolização, oxidação ou degradações químicas.

Os rizomas foram preparados de duas maneiras: "in natura", inteiros e limpos, simplesmente embalados e conservados a $-18{ }^{\circ} \mathrm{C}$ e "in natura", secados inteiros em estufa com circulação de ar (Fanne, modelo 170), por 8 horas, até a redução de sua umidade para $10 \%$ e estocados $-18{ }^{\circ} \mathrm{C}$.

\subsection{EXTRAÇÃO}

Quatro métodos de extração com solventes orgânicos distintos foram testados com a finalidade de se obter a resina e o óleo, além da extração de óleos voláteis por arraste de vapor.

\subsubsection{Extração com solventes orgânicos}

Os materiais empregados nesta técnica foram:

a) Solventes de grau p.a.

- ÁLCOOL ETílICO

- N-HEXANO

- ACETONA

- ÉTER ETílico.

b) Vidraria

- Acessórios comuns em laboratório (copo de béquer, proveta, dessecador e outros)

- Extrator de Soxhlet, 250 mL, com juntas esmerilhadas e cônicas.

c) Equipamentos

- Manta aquecedora (Fisatom, modelo 52)

- Balanças analíticas (Mettler, modelos H6 e AE-50)

- Estufa (Fanem de secagem, modelo 315 SE)

- Cartuchos de extração (33 x $94 \mathrm{~mm})$

- Cronômetro (Cassio HS-10W)

- Nitrogênio super seco (White Martins). 
As amostras do rizoma, "in natura" seco, foram retiradas do congelador e raladas, para obtenção de partículas com diâmetro médio de $1 \mathrm{~mm}$. Poucos minutos antes do processamento foram pesadas analiticamente, em cartuchos próprios para a extração, com massa de, aproximadamente, 15 gramas. O cartucho contendo o rizoma, ralado e pesado, foi tampado com algodão e colocado no extrator. No balão de destilação, houve a adição de $200 \mathrm{~mL}$ de solvente, completando-se a montagem do sistema junto ao condensador. A temperatura de aquecimento da manta foi mantida em torno de $200{ }^{\circ} \mathrm{C}$, proporcionando ciclo de refluxo entre 7 e 8 minutos, dependendo do ponto de ebulição do solvente. Em paralelo ao aquecimento, iniciou-se a refrigeração do condensador.

O processo de extração foi mantido durante 7 horas, contadas a partir do primeiro refluxo. O balão foi retirado do conjunto extrator e mantido em aquecimento na temperatura de $30{ }^{\circ} \mathrm{C}$, sob fluxo de nitrogênio, para evaporar todo o solvente. A diferença de peso no balão, obtida antes e depois da extração, resultou no teor da resina extraída.

\subsubsection{Extração por percolação simples e com vapor}

Na percolação simples a água foi aquecida até a ebulição e aplicada no processo, em estado líquido.

No método de percolação com vapor, o vapor d'água foi passado por uma coluna contendo o material. A matéria-prima utilizada foi o rizoma, previamente preparado. Nestas análises foram utilizados os seguintes materiais e equipamentos:

a) Solvente

- água destilada.

b) Vidraria

- coluna com placa grossa filtrante $(30 \times 300 \mathrm{~mm})$

- frasco de Kitasato $(1000 \mathrm{~mL})$

- junta conectante de 3 vias (ângulo de $75^{\circ}$ )

- erlenmeyer $(500 \mathrm{~mL})$

- proveta

- cápsulas de porcelana.

c) Equipamentos

- aquecedor elétrico (Prodicil, modelo 01)

- balança analítica (Sartorius, mod. A-200 S)

- termômetro (Incoterm-ASTM 9 C, faixa 5 a $110^{\circ} \mathrm{C}$ )

- cronômetro (Cassio HS IO W)

- banho-maria (Fanem). 
Para o processamento de percolação simples foram colocadas $300 \mathrm{~g}$ de amostra na coluna (Figura 1), preenchendo $3 / 4$ do seu volume. Adicionaram-se, então, $300 \mathrm{~mL}$ de água fervente e o líquido, percolado através da massa, foi coletado por um erlenmeyer na saída da coluna.

Na extração com percolação de vapor, o vapor foi gerado em Kitasato e percolado através do material, condensando-se na saída da coluna e também coletado por erlenmeyer. A Figura 2 mostra o aparato da extração.

Um termômetro instalado na junta de entrada da coluna indicou a temperatura.

\section{FIGURA 1 - EXTRATOR DE PERCOLAÇÃO SIMPLES}

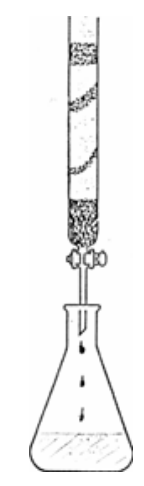

\section{FIGURA 2 - EXTRATOR DE PERCOLAÇÃO À VAPOR}

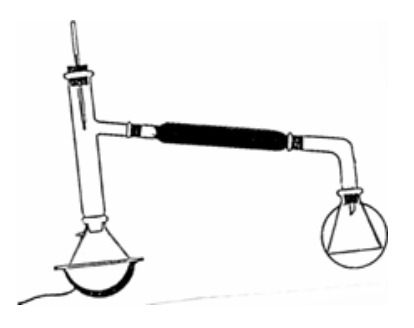

As diferenças nos pesos do material revelaram os rendimentos mássicos das matérias extraídas. 


\subsubsection{Extração de óleo por arraste de vapor}

O método consiste em aquecer o material (rizoma) e a água juntos, num recipiente conectado ao separador de fases ao condensador. O óleo por ser volátil é evaporado da massa sólida e condensa-se, separando-se do líquido por densidade. Este procedimento de extração de óleos essenciais é descrito mais detalhadamente pela AOAC, métodos $\mathrm{n}^{\circ} 30.020,30.021$ e 30.025 (2).

Para execução do processo foram utilizados:

a) Solvente

- água destilada.

b) Vidraria

- conjunto extrator (Figura 3)

- extrator para óleos essenciais, segundo a AOAC

- balão de destilação $(1000 \mathrm{~mL})$

- condensador Friedrichs, com junta inferior.

\section{FIGURA 3 - EXTRATOR DE ÓLEO}

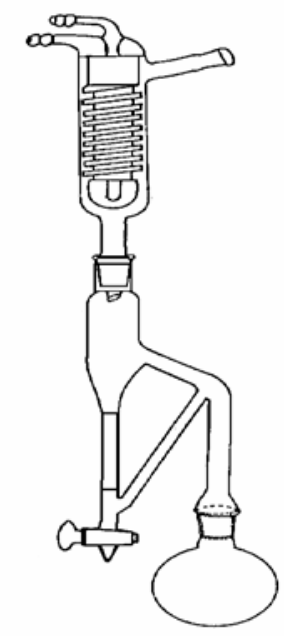

c) Equipamentos

- manta de aquecimento (Fisaton, modelo 102)

- balança analítica (Sartorius, mod. A-200-S). 
Em análises consecutivas, com o mesmo tempo de duração e em datas seqüenciais foram realizadas extrações de óleo, com a finalidade de avaliar as mudanças decorrentes em sua composição, pela permanência do material em contato com o calor. Os tempos fixados foram $2 \mathrm{~h}, 4 \mathrm{~h}$, $6 \mathrm{~h}, 12 \mathrm{~h}, 24 \mathrm{~h}$ e 48 horas.

O óleo obtido foi seco em coluna com sulfato de sódio anidro e levado para armazenamento a $-18{ }^{\circ} \mathrm{C}$ em congelador. $\mathrm{O}$ frasco de armazenamento, constituído de polietileno, foi recoberto com papel alumínio para não permitir o contato do óleo com a luz. Para amenizar oxidações, manteve-se fluxo de nitrogênio dentro do frasco, antes de fechá-lo.

\subsection{ENSAIOS DE CARACTERIZAÇÃO DA MATÉRIA-PRIMA}

Os reagentes e equipamentos utilizados nas determinações de caracterização da matéria-prima atenderam os métodos padronizados pelo Instituto Adolfo Lutz (IAL) e pela $\operatorname{AOAC}(2,26)$.

\subsubsection{Composição básica do vegetal $(2,26,27)$}

- Lipídios (método 4.10/IAL)

- Fibras (método 4.15/IAL)

- Proteínas (método 2.055/AOAC)

- Açúcares (redutores em glicose - método 4.13.2/IAL e não redutores em sacarose - método 4.13.3/IAL)

- Cinzas (método 3.004/AOAC)

- Umidade (método 7.007/AOAC).

\section{5 ENSAIOS DE CARACTERIZAÇÃO DO ÓLEO $(2,26)$}

\subsubsection{Densidade}

Para determinar a densidade do óleo foi utilizado o método 28.006 da AOAC.

\subsection{2 Índice de refração}

Utilizou-se o método 28.009/AOAC, com refratômetro Zeiss Opton (Germany - Nr. 123.625). 


\subsubsection{Umidade}

Para determinação da umidade, os ensaios foram realizados com o equipamento "Aquatest IV - Fotovolt, pelo método Karl Fischer.

\subsubsection{Ensaios espectrométricos}

\subsubsection{Espectrometria no infravermelho}

Os ensaios de espectrometria no infravermelho foram realizados em equipamento Beckmann, em filme líquido, com janelas de cloreto de sódio.

\subsubsection{Espectrometria de massas}

Utilizou-se detetor de massas, acoplado em cromatógrafo HP 5890, para identificar os componentes de cada grupo. O método baseia-se na fragmentação iônica das moléculas componentes do óleo mediante feixe de elétrons. Um dispositivo eletrônico registra o resultado, sob a forma de fragmentos iônicos positivos. O espectro de massas, assim obtido, permite identificar, pelo estudo dos fragmentos, os componentes do óleo.

\subsection{LIMPEZA NO MATERIAL UTILIZADO}

Toda a vidraria e demais acessórios de laboratório utilizados nas análises foram cuidadosamente limpos com auxílio do detergente Extran (Merck). Após a lavagem o material foi enxaguado, no mínimo 3 vezes, com água destilada.

\section{RESULTADOS E DISCUSSÃO}

No Quadro 4 constam os rendimentos de extração com diversos solventes, em extrator de Soxhlet.

Pode-se observar que há grande diferença nos rendimentos de extração em Soxhlet quando as condições são alteradas. Isto justifica as diferenças encontradas entre estes resultados e os apresentados na literatura, que não especificam as condições operacionais do processo.

O rendimento obtido para o extrato cetônico (11.08\%) foi 53,4\% superior ao encontrado na literatura (Quadro 5), enquanto os resultados para 0 extrato etéreo não foram significativos (3,0\%). LAWRENCE (21) obteve rendimentos de 7,2\% (v/m) empregando acetona e 6,9\% (v/m) para 0 álcool, sempre utilizando o rizoma seco como ponto de partida para 0 
processo. Neste trabalho os ensaios foram realizados com o rizoma úmido e como o solvente e a resina são solúveis em água, acréscimo na concentração, devido a diluição do extrato, justificaria as diferenças no resultado.

\section{QUADRO 4 - EXTRAÇÃO POR SOLVENTES ORGÂNICOS}

\begin{tabular}{|c|c|c|c|}
\hline SOLVENTE(100 mL) & $\begin{array}{l}\text { MATÉRIA- } \\
\text { PRIMA }\end{array}$ & $\begin{array}{l}\text { CONDIÇÕES DE } \\
\text { EXTRAÇÃO }\end{array}$ & $\begin{array}{c}\text { RENDIMENTOS } \\
\% \mathrm{~m} / \mathrm{m}\end{array}$ \\
\hline $\begin{array}{c}\text { Álcool : Água } \\
\text { 80:20 }\end{array}$ & $\begin{array}{l}\text { "in natura" } \\
\text { ralada }\end{array}$ & $\begin{array}{c}\text { Massa }=19 \mathrm{~g} \\
\text { Tempo }=7 \mathrm{~h} \\
\text { Temperatura na manta de } \\
\text { aquecimento }=180^{\circ} \mathrm{C}\end{array}$ & 2,2 \\
\hline n-Hexano & $\begin{array}{l}\text { "in natura" } \\
\text { ralada }\end{array}$ & $\begin{array}{c}\text { Massa }=15 \mathrm{~g} \\
\text { Tempo }=7 \mathrm{~h} \\
\text { Temperatura na manta de } \\
\text { aquecimento }=95^{\circ} \mathrm{C}\end{array}$ & 0,36 \\
\hline n-Hexano & $\begin{array}{l}\text { "in natura" } \\
\text { ralada }\end{array}$ & $\begin{array}{c}\text { Massa }=15 \mathrm{~g} \\
\text { Tempo }=3 \mathrm{~h} \\
\text { Temperatura na manta de } \\
\text { aquecimento }=95^{\circ} \mathrm{C}\end{array}$ & 0,32 \\
\hline Acetona & $\begin{array}{l}\text { "in natura" } \\
\text { ralada }\end{array}$ & $\begin{array}{c}\text { Massa }=10 \mathrm{~g} \\
\text { Tempo }=4 \mathrm{~h} \\
\text { Temperatura na manta de } \\
\text { aquecimento }=95^{\circ} \mathrm{C}\end{array}$ & 2,2 \\
\hline Acetona & $\begin{array}{c}\text { seco e } \\
\text { macerado }\end{array}$ & $\begin{array}{c}\text { Massa }=10 \mathrm{~g} \\
\text { Tempo }=3 \mathrm{~h} \\
\text { Temperatura na manta de } \\
\text { aquecimento }=95^{\circ} \mathrm{C}\end{array}$ & 11,08 \\
\hline Éter Etílic0 & $\begin{array}{c}\text { seco e } \\
\text { macerado }\end{array}$ & $\begin{array}{c}\text { Massa }=10 \mathrm{~g} \\
\text { Tempo }=4 \mathrm{~h} \\
\text { Temperatura na manta de } \\
\text { aquecimento }=60^{\circ} \mathrm{C}\end{array}$ & 3,0 \\
\hline
\end{tabular}

Obs.: Resultados de rendimento em extrato seco.

Uma das desvantagens na aplicação de solventes orgânicos é que estes extraem além dos componentes aromáticos, outras substâncias como: matéria graxa, ácidos orgânicos, açúcares oligossacarídios, matéria colorida e outros $(4,5)$.

No presente trabalho, as temperaturas de extração não superaram $180^{\circ} \mathrm{C}$ para não possibilitar a degradação do gingerol em shogaol e gingerona, como sugerem CHU-CHIN CHEN e CHI-TANG HO $(8,9,10)$. 


\section{QUADRO 5 - RENDIMENTO DE EXTRATOS ORGÂNICOS}

\begin{tabular}{|l|c|c|}
\hline Autor & Extrato Cetônico & Extrato Etéreo \\
\hline LAWRENCE (21) & $7,2 \%$ & $*$ \\
\hline LEVERINGTON (22) & $4,5 \%$ & $4,2 \%$ \\
\hline GOVINDARAJAN (14) & $6,9 \%$ & $3,3 \%$ \\
\hline
\end{tabular}

*não indica resultado

As resinas obtidas apresentaram-se viscosas e de cor marrom-amarelada.

O n-Hexano, por ser apolar, apresentou resultados muito inferiores aos dos outros solventes, porém compatíveis com aqueles indicados por LAWRENCE (21). Segundo este autor o n-Hexano é um bom solvente para a obtenção de óleos essenciais, porém como não extrai substâncias polares, apresenta baixos rendimentos.

O material seco e macerado, quando extraído com éter etílico, apresentou rendimentos condizentes com os da literatura, o que não sucedeu com a extração pela acetona, que resultou em índices superiores aos indicados .

Para a extração com água, as condições de trabalho e resultados foram:

- Extrato aquoso seco: 2,3\% m/m

- Matéria-prima : "in natura" ralada

- Massa : $15 \mathrm{~g}$

- Tempo de extração : 7 horas

- Temperatura na manta de aquecimento : $280{ }^{\circ} \mathrm{C}$.

Citando Natarajan, LAWRENCE (21) apresentou resultados para o gengibre indiano $(19,6 \% \mathrm{~m} / \mathrm{m}$ de extrato aquoso seco) que diferem significativamente daqueles apresentados neste trabalho. Possivelmente esta diferença relaciona-se ao sistema de extração e separação empregada pelo autor, que não descreve a técnica e as fórmulas de cálculo em seu artigo.

Os métodos de extração testados, por percolação com água, resultaram em extratos muito diluídos, de cor marrom escura e odor característico do rizoma. A eliminação da água, necessária para a obtenção do extrato puro, foi demorada (cerca de 8 horas), pois a temperatura não pode exceder $80{ }^{\circ} \mathrm{C}$. Acima deste valor, o material junto à parede do frasco pode carbonizar, provocando degradação do gingerol e alterações significativas no aroma. 
O processo de obtenção do extrato por percolação "a quente" é inferior ao obtido por extração de vapor, segundo LAWRENCE (21). Tal fato foi constatado, pois o registro da literatura é de $15 \%$ e o deste trabalho apontou $13 \%$, enquanto a extração por percolação a vapor apresentou $52 \% \mathrm{~m} / \mathrm{m}$.

Segundo a AOAC (2) a utilização de arraste de vapor resulta na obtenção de óleo muito aromático, de cor amarela cristalina. Dos procedimentos de extração testados, este foi o único em que o óleo se separou nitidamente, da água. Os resultados obtidos neste processo foram:

- Massa de matéria-prima: $300 \mathrm{~g}$

- Teor médio do óleo (extraído em base seca de matéria-prima): 2,49\%, com coeficiente de variação entre os resultados de 10,11\%

- Umidade da matéria-prima: 85,48\%, com coeficiente de variação entre os resultados de $2,5 \%$

- Temperatura da manta de aquecimento: $185^{\circ} \mathrm{C}$.

- Tempos de extração: 2, 4, 6, 12, 24 e 48 h.

A temperatura na manta de aquecimento foi controlada, de modo a não permitir que o material, dentro do balão de extração e em contato com a parede do frasco, não carbonizasse, resultando num odor característico de açúcar queimado.

A quantidade de óleo extraída foi indicada pela coluna graduada do separador de fases e registrada antes da secagem. $O$ procedimento de secagem do óleo resultou na perda de $5 \% \mathrm{v} / \mathrm{v}$ do volume total percolado pela coluna. Ensaios cromatográficos realizados com o óleo, com ou sem processo de secagem, apresentaram os mesmos resultados na sua composição, comprovando que o sulfato de sódio anidro é inerte a este óleo, não causando interferência detectável em sua composição e também no aroma. No Quadro 6 constam os resultados encontrados na extração do óleo do gengibre úmido.

\section{QUADRO 6 - RENDIMENTO DO ÓLEO EM \% VIM}

\begin{tabular}{|l|c|c|c|}
\hline MATERIAL & $\begin{array}{c}\text { TEMPERATURA } \\
\left({ }^{\circ} \mathrm{C}\right)\end{array}$ & $\begin{array}{c}\text { TEMPO } \\
(\mathrm{h})\end{array}$ & $\begin{array}{c}\text { ÓLEO } \\
(\% \mathrm{~V} / \mathrm{M})\end{array}$ \\
\hline \multirow{3}{*}{$\begin{array}{l}\text { Rizoma "in natura“ } \\
300 \text { gramas }\end{array}$} & 98 & 2 & 2,37 \\
\cline { 2 - 4 } & 98 & 4 & 2,50 \\
\cline { 2 - 4 } & 98 & 6 & 2,53 \\
\cline { 2 - 4 } & 98 & 12 & 2,61 \\
\cline { 2 - 4 } & 98 & 24 & 2,62 \\
\cline { 2 - 4 } & 98 & 48 & 2,65 \\
\hline
\end{tabular}


A otimização do processo de extração do óleo de gengibre empregado neste trabalho produziu resultados superiores aos da literatura.

Os resultados mostraram que a melhor qualidade do óleo é obtida pelo processo de arraste de vapor, com tempo de extração de 2 horas, e que a maior quantidade de resina é obtida utilizando a propanona como solvente e tempo de extração de 3 horas.

O gengibre do litoral do Paraná ainda ficou caracterizado pela determinação das suas constantes físicas, pelo espectro no infravermelho e identificação provável de vários componentes de seu óleo por cromatografia em fase gasosa e espectrometria de massas.

\begin{abstract}
The present work describes the processes used for the obtention of ginger oil and resin, extracted from its rhizome and processed. The analysis were conducted with natural rhizome, harvested, washed and mantained by refrigeration until the moment of use and dried in an air stove until it reaches moisture content of $10 \%(\mathrm{~m} / \mathrm{m})$ and finally stored by refrigeration. The obtention processes of oil involved the extraction with organic solvents, to achieve the resins and oil, and steam stripping for oil. The results showed that the best quality of the oil is achieved by the steam stripping process, with 2 hours of extraction and that the higher quantity of resin is obtained by the use of propanone as solvent and extraction time of 3 hours.
\end{abstract}

\title{
REFERÊNCIAS BIBLIOGRÁFICAS
}

1 ANAND, N. Selected markets for ginger and its derivatives with special reference to dried ginger. London : Tropical Products Institute, 1982.

2 AOAC. Official methods of analysis of the association of official analytical chemists. Washington, 1980.

3 ARAEZ, H. GARCIA. Perfumes sintéticos, su química y preparacion. Madrid : Aguilar, 1951.

4 BEDNARCZYK, A.A., KRAMER, A. Pratical approach to flavor development. Food Technology, v. 25, p. 1098-1107, 1971.

5 BEDNARCZYK, A.A., KRAMER, A. Identification and evolution of the flavor: significant components of ginger essential oil. Chemical Senses and Flavor, Holanda, v. 1, p. 377-86, 1975. 
Cosmetiques, Aromes, v. 63-61, Juin/Juil, 1985.

$7 \quad$ BROWN, B.I. Processing and preservation of ginger by syruping under atmospheric conditions. Food Technology, v. 23, n. 87, p. 87-91, Jan. 1969.

8 CHU-CHIN CHEN, CHI-TANG HO. Gas chromatografic analysis of thermal degradation of gingerol compounds in steam: distilled oil from Ginger. Chromatografy, Amsterdan, v. 19, p. 499-504, 1987.

$9 \quad \mathrm{CHU}-\mathrm{CHIN}$ CHEN et al. High performance liquid chromatographic determination of pungent gingerol compounds of ginger. Journal of Food Science, v. 51, n. 5, p. 364-65, 1986.

10 CHU-CHIN CHEN et al. Chromatography analyses of isomeric shogaol compounds derived from isolated gingerol compounds of ginger (Zingiber officinale Roscoe). J. Chromatography. Amsterdan, v. 360, n. 6, p. 175-84, 1986.

11 CONNEL, D.W., JORDAN, R.A. Composition and distinative volatil.e flavour characteristics of the essential oil from Australian, grown ginger (Zingiber officinale). J. Sci. Food Agric., v. 22, p. 93-95, 1971.

12 CONNEL, D.W. Chemical composition of certain products from ginger (Zingiber officinale). Australian Chemical Processing and Engineering, v. 27, Nov. 1971.

13 EDWARDS, D. The market for dried, preserved and fresh ginger. London : TPI, 1975.

14 GOVINDARAJAN, V.S. Ginger: chemistry, technology and quality evaluation, Part I. CRC Critical Reviews in Food Science and Nutrition, Quensland, v. 17, p. 98, 1982.

GOTO, R. Efeitos de fitorreguladores na emergência e desenvolvimento de gengibre (Zengiber officinale, Roscoe). São Pedro : Centro de Raízes Tropicais/UNESP/SBM, 1996 .

GUENTHER, E. The essential oils. London : D. Van Nostrand, 1967. $132 \mathrm{p}$.

17 HASSANEN, N.Z.S. Extraction of alseed model systems with alcohols. Dissertation Abstracts Internacional, Texas, v. 46, n. 10, p. 301-13, 1986 . 
KAMI, T. et al. Volatile constituents of Zingiber Oficinale.

Phytochemistry, Inglaterra, v. 11, n. 11, p. 3377-81, 1972.

19 KEPNER, R.E., MAARSE, H. Hydrogenolysis of terpenes in the injection pan of a gas chromatograph. Journal of Chromatography, v. 66, p. 229-37, 1972.

20 LANA, M.M., CASALI, V.W.D., FINGER, F.L., REIS, F.P. Avaliação da conservação pós-colheita de rizomas de gengibre. Horticultura Brasileira, Brasília, v. 11, n. 2, p. 139-141, nov. 1993.

21 LAWRENCE, B.M. Major tropical spices - ginger (Zingiber oficinale Roscoe). Perfurmer \& Flavorist, Illinois, v. 9, n. 5, p. 1-40, 1984.

22 LEVERINGTON, R.E. Ginger technology. Food Technology in Australia, Hamilton, p. 303-313, Aug. 1975.

23 MANUAL de taxomania vegetal: plantas de interesse econômico. São Paulo : Nobel, 1981. 197 p.

24 MATHEW, A.G. et al. Oil of ginger. The Flavour Industry, India, v. 4, p. 226-29, 1973.

25 MONTALDO, A. Cultivo de raices y tuberculos tropicales. 2.ed. San Jose : IICA, 1991.

26 NORMAS analíticas do Instituto Adolfo Lutz. 3.ed. São Paulo, 1985. $533 \mathrm{p}$.

27 OKOL, P.N. A assesment of the protein mineral and vitamin losses in sun-dried nigeria vegetables. Nutrition Reports International, Nigeria, v. 29, n. 2, p. 359-64, Feb.1984.

28 PICKETT, J.A. et al. Distorcion of essential oil composition during isolation by steam distillation. Chemistry and Industry, p. 557172, Jul. 1975.

29 SALZER, U.J. Analytical evaluation of seasoning extracted (oleoresins) and essential oils from seasonings II. Flavours, p. 206-10, Jul./Aug., 1975.

30 SINGH, I.P. et al. Tentative identification of various components and fatty acids of ginger lipids. Indian Journal Agriculture Science, v. 45, n. 11-12, p. 545-49, 1975.

31 STAHL, E. Solubility behaviour and fraction of essentai oils in dense carbon dioxide. Perfumer \& Flavorist, v. 10, p. 29-37, Apr./May, 1985. 
32 TANGEL, F.P. Determination of the aging mechanism of ginger extract used in the manufacture of ginger ale. C.R.C. Crit. Rev. Food Sci. Nutr., v. 23, n. 87, 187-91, Jan.1969.

33 TAVEIRA MAGALHAES, M., KOKETSU, M., GONCALVES, S.L., DUARTE, F.R., GODOY, R.L. de O., LOPES, D. Gengibre (Zingiber officinale Roscoe) brasileiro: aspectos gerais, óleo essencial e óleo-resina. Parte 1 - Aspectos gerais, óleo essencial. Ciência e Tecnologia de Alimentos, Campinas, v. 17, n. 1, p. 64-69, jan./abr. 1997.

34 TEIXEIRA, Z. da S., ALMEIDA, M.S.B., RASSY, M.E. de C., ALVES, E.T. Plantas medicinais mais conhecidas na comunidade de previnciaria e a realidade quanto a seu uso. Belém: Escola de Enfermagem Magalhães Barata, 1986.

35 UPOV (Geneva, Suiça). Guidelines for the conduct of tests for distinctness, uniformity and stabilit: ginger (Zingiber officinale Rosc.). Geneva, 1996.

36 WINNINGER, J.A, et al. High resolution infrared spectra of some naturally occuring sesquiterpene hydrocarbons. Journal of the A.O.A.C., v. 50, n. 6, p. 1313-34, 1967.

37 BOLETIM do Banco Central do Brasil: relatório 1998. Disponível: http://www.bcb.gov.br/htms/Banual98/banual.shtm [capturado em 5 ago. 1999]. 